\title{
Nilai, Makna, dan Simbol Dalam Pertunjukan Wayang Golek Sebagai Representasi Media Pendidikan Budi Pekerti
}

\author{
Cahya \\ Institut Seni Budaya Indonesia (ISBI) Bandung \\ Jl. Buahbatu No.212 Bandung
}

\begin{abstract}
This paper raises the issue of meaning and values contained in a puppet show spectacle purwa as a form of folk who still has the characteristics ketradisiannya. A puppet show for this is still seated was not just art that entertain spectators, but more than that, a puppet show is able to give meaning and value to the life of society and culture.

Understood as a form of spectacle, guidance and order, then the puppet show not only seated as edhipheni art, but also as art bersrata adhiluhung. One characteristic of these keadhiluhungannya charges that have value philosophy of life that includes the moral, religious, ethical and aesthetic. Such values can be found in the content of the play or story presented by puppeteer, through working on Antawacana pembendaharaan form (dialog puppet) in accordance with the character and the character of the puppet.

With regard to the charge of those values, then the form of a puppet show into a reality of life as an inspiring value of character education for social life and culture.
\end{abstract}

Keywords: puppet, value, meaning, manners.

\begin{abstract}
ABSTRAK
Tulisan ini mengangkat persoalan makna dan nilai-nilai yang terdapat dalam pertunjukan wayang golek purwa sebagai sebuah bentuk tontonan rakyat yang masih memiliki ciri-ciri ketradisiannya. Pertunjukan wayang golek selama ini masih didudukkan tidak sekadar seni yang menghibur penontonnya, akan tetapi lebih dari itu, pertunjukan wayang golek mampu memberikan makna dan nilai bagi kehidupan bermasyarakat dan berbudaya.Bentuk tulisan ini pun merupakan perasan dari hasil penelitian yang menggunakan metode kualitatif dengan pendekatan multidisiplin terutama berkaitan dengan nilai kefilsafatan dan estetika pedalangan.

Dipahami sebagai sebuah bentuk tontonan, tuntunan, dan tatanan, pertunjukan wayang tidak hanya didudukkan sebagai seni yang edhipheni, tetapi juga sebagai seni yang bersrata adhiluhung. Salah satu ciri keadhiluhungannya tersebut yaitu memiliki muatan-muatan nilai filosofi kehidupan yang meliputi nilai moral, religi, etika, dan estetik.Nilai-nilai tersebut dapat dijumpai dalam isi lakon atau cerita yang disajikan oleh dalang, melalui pembendaharaan bentuk garap antawacana (dialog wayang) sesuai dengan tokoh dan karakter wayangnya.

Adapun hasil atau capaian dari penelitian ini, dapat disimpulkan bahwa, pertunjukan wayang golek menjadi sebuah realitas nilai kehidupan sebagai inspirasi pendidikan budi pekerti bagi kehidupan bermasyarakat dan berbudaya.
\end{abstract}

Kata kunci: wayang golek, nilai, makna, budi pekerti. 


\section{PENDAHULUAN}

Wayang adalah salah satu manipestasi budaya luhur bangsa Indonesia yang secara historis, dikenal sejak tahun $861 \mathrm{M}$ pada masa raja Jayabaya di Mamenang Kediri.Oleh karena itu, bagi masyarakat Indonesia khususnya Jawa (barat, tengah, dan timur) tidak terlepas dari pertunjukan wayang sebagai bagian dari kehidupannya.Wayang dikenal sebagai seni pertunjukan yang edipeni-adiluhung, yang artinya seni yang mengandung nilai-nilai keindahan dan bermuatan ajaran moralspiritual yang dalam.Melalui pertunjukan wayang, dalam menyampaikan pesanpesan moral yang bermanfaat besar bagi terwujudnya character building sekaligus sebagaipendidikan budi pekerti. Melalui pertunjukan wayang, krisis moral dan disorientasi budaya yang kini sedang melanda peradaban budaya bangsa Indonesia, secara perlahan akan dapat dieliminir menuju kearah sadar akan potensi budaya kelokalan yang bernilai luhur dan berdaya guna bagi generasi bangsa dan negara.

Berdasar kepada fakta dan realitas budaya tersebut, tidak mengherankan ketika tahun 2003 UNESCO sebagai salah satu badan dunia menobatkan wayang Indonesia sebagai Masterpiece of the Oral and Intangible Heritage of Humanity, wayang sebagai karya agung dunia. Kenyataan menunjukkan bahwa wayang sejak dulu hingga sekarang tetap hidup dan berkembang di masyarakat seiring dengan perkembangan zamannya.Di samping itu, pertunjukan wayang memiliki kualitas seni yang tinggi sehingga perlu dilestarikan dan dikembangkan agar bermanfaat bagi kehidupan berbangsa dan bernegara. Alasan-alasan inilah yang menjadi pertimbangan dan pengakuan dunia terhadap eksistensi seni pertunjukan wayang di Indonesia.
Seni pertunjukan wayang dalam hal ini adalah seni wayang golek yang hidup dan berkembang di wilayah budaya tatar Sunda, dipandang sebagai salah satu bentuk tontonan rakyat yang kental dengan nilai-nilai kerakyatannya.Sebagai sebuah bentuk tontonan, pertunjukan wayang golek selalu berhubungan erat dengan berjubelnya penonton yang terdiri atas berbagai lapisan masyarakat, kesemuanya bertujuan untuk menonton pertunjukan wayang. Peran dan kedudukan dalang sebagai aktor utama dalam pertunjukan wayang, dituntut untuk mampu menyajikan gaya pertunjukannya dalam upaya memberi kepuasan kepada penonton. Kepiawaian memainkan wayang (sabet), membawakan lakon atau cerita, menyampaikan dialog wayang (antawacana), menyanyikan kakawen (Jawa: Suluk), menyajikan humor (banyol) dan aspek-aspek lainya adalah tugas berat yang harus dilakoni oleh seorang dalang.

Di samping sebagai tontonan, misi berikutnya adalah pertunjukan wayang sebagai tuntunan. Tidak hanya sekadar memberikan hiburan yang segar bagi para penontonnya, tetapi melalui lakon dalam cerita yang disajikan oleh dalang dapat memberikan ajaran moral dan nilai-nilai keutamaan kehidupan. Setiap lakon dalam cerita pewayangan selalu mengarah kepada sebuah tema yang berkaitan erat dengan fenomena dan realitas kehidupan.Seperti halnya tema kepahlawanan (patriotisme), kesetiaan, kepemimpinan, perkawinan, kelahiran, perebutan hak kepemilikan, pendalaman ilmu, dan lain-lain. Tematema tersebut akan tersajikan secara simbolik dengan muatan nilai-nilai kehidupan yang dapat memberikan bekal sebagai tuntutan bagi penonton setelah menyaksikan pertunjukan wayang. Hikmah di balaik cerita yang terdapat 
dalam lakon pewayangan tersebut, pada akhirnya dapat meneladani hal-hal yang baiknya, serta dapat bercermin kepada halhal keburukan, kejahatan, keangkaramurkaan yang diperankan oleh tokohtokoh wayang antagonis.

Misi berikutnya setelah wayang berperan sebagai tontonan dan tuntunan, juga pertunjukan wayang adalah sebagai tatanan nilai-nilai keindahan yang bersentuhan dengan rasa estetik (keindahan) yang dirasakan langsung oleh penonton. Berkenaan dengan rasa penikmatan sebagai bentuk respon estetik antara pertunjukan wayang dan penontonnya, kesemuanya dapat tersaji secara audio-visual.Secara kasat mata, pertunjukan wayang mampu menunjukkan sebuah bentuk tatanan estetik yang artistik dengan susunan dan tata letak penempatan alat-alat pendukung pertunjukan seperti perangkat gamelan, jagat pagelaran wayang (gedebog pisang), janturan wayang (deretan wayang samping kiri dan kanan dalang), tata lampu, sound system, dan lain-lain.Adapun tatanan estetik auditif adalah dapat tersajikan melalui hidangan bunyi-bunyian, baik dari suara dalang (haleuang kakawen, haleuang wayang, dialog wayang), suara sinden maupun suara gamelan yang mengiringi alunan pertunjukan wayang.Kesan-kesan seperti itulah yang kesemuanya dapat memanjakan penonton dalam menikmati tontotan, tuntunan, dan tatanan dalam pertunjukan wayang.

Menyoal keterkaitan antara pertunjukan wayang dan konteks pendidikan budi pekrti, adalah sebuah bentuk kesatuan nilai dan makna yang keduanya saling mengkait.Pendidikan budi pekerti bagi para generasi penerus menjadi kata kunci yang pundamental, yang harus tertanamkan sejak dini sebagai landasan hidup bermasyarakat, berbangsa, dan bernegara.
Krisis moral yang kini sedang menjamur menjadi virus yang mengerikan menyangkut masa depan sikap dan martabat bangsa, sehingga apabila dibiarkan tanpa ada upaya penyelamatan dan pemeliharaan nilai moral jati diri bangsa, "kehancuran" bangsa dapat menjadi kenyataan. Kekhawatiran inilah yang harus menjadi perhatian dan komitmen kita semua, bagaimana membangun dan membentuk character building melalui sistem, baik formal maupun non formal.

Melalui pertunjukan wayang, proses pendidikan budi pekerti dapat tersajikan dengan muatan nilai-nilai kepribadian sikap dan mentalitas yang terdapat dalam karakter dari masing-masing tokoh wayang. Ajaran moral yang terkandung dalam pertunjukan wayang tidak hanya berupa wacana, akan tetapi ditampilkan dalam praktik kehidupan sehari-hari berupa sikap dan perilaku. Sebagai contoh nilai kejujuran dan kebijakan terdapat dalam tokoh Darmakusumah sang raja Amarta, nilai keberanian pada Bima yang tidak takut menegakan kebenaran, nilai kesetiaan pada Anoman yang loyal dengan ketulusan pengabdiannya menegakan keadilan dan kebaikan, nilai cinta tanah air (nasionalisme) terdapat pada Kumbakarna yang berani berkorban demi keselamatan bangsa dan negara.

Pada dasarnya, pertunjukan wayang adalah sebuah dunia penuh makna sekaligus sebagai etalase nilai-nilai kehidupan dengan kedalaman makna dan simboliknya. Lakon dalam pertunjukan wayang memberi gambaran nyata tentang adanya dua lisme alam papasangan yaitu perang antara kebaikan dan keburukan. Lambang kebenaran ditunjukkan oleh dalang dengan menempatkan tokoh wayang diletakkan pada bagian sebelah kanan dalang, adapun lambang keburukan 
(kejahatan) diletakkan pada bagian sisi kiri dalang.Di manapun, siapapun dalangnya, yang baik pasti menang, yang jahat pasti kalah. Secara tidak langsung, proses pendidikan budi pekerti melalui pertunjukan wayang dapat berjalan dengan sendirinya, secara alamiah penonton dapat mencerna dan memaknai betapa pentingnya manusia Indonesia berbudi pekerti yang baik, bermoral, bermartabat, dan berahlak luhur sebagai cita-cita bangsa Indonesia seutuhnya.

\section{METODE}

Untuk memperoleh sumber berupa data yang kredibel serta relevan dengan permasalahan yang diteliti, diperlukan sebuah metode penelitian sebagai piranti membedah dan mengungkap dari berbagai permasalahan terkait. Penelitian ini adalah bersifat kualitatif, dengan demikian dasar yang dipakai untuk analisisnya adalah data, kehadiran data harus ditempatkan sebagai sebuah totalitas (Soedarsono, 1999, 8-12). Sebuah bentuk penelitian kualitatif, data yang diperlukan dari berbagai sumber itu pun adalah berbentuk data kualitatif. Salah satu sifat dari data kualitatif adalah bahwa data itu merupakan data yang memiliki kandungan yang kaya, yang multi-dimensional, dan kompleks. Sebuah data kualitatif ibarat sebuah 'teka-teki' atau sebuah 'misteri'. Dalam menebak teka-teki itu selalu harus mengarah untuk menjawab pertanyaan 'mengapa', dan bukan sekadar menjawab pertanyaan 'apa' (Soedarsono, 1999,46). Salah satu yang dapat mencirikan dari bentuk penelitian kualitatif ini adalah mengedepankan bentuk pertanyaan 'mengapa' kemudian dieksplanasi dengan secermat mungkin dalam upaya menuju pada hasil penelitian yang berkualitas. Kekuatan menafsir, memahami, menginterpretasi, dan menganalisis juga merupakan menu utama dalam penelitian kualitatif sehingga metodologinya pun berbentuk deskriptif analisis.

\section{HASIL DAN PEMBAHASAN \\ Falsafah dalam Pertunjukan Wayang Golek}

Untuk memahai falsafah dalam pertunjukan wayang, nampaknya perlu dipaparkan terlebih dahulu mengenai kedudukan filsafat dalam perspektif disiplin ilmu.Sebagaimana disebutkan oleh Alan R.Drengson, bahwa filsafat dibagi menjadi tiga, yaitu filsafat non-eksplisit, filsafat sistematis, dan filsafat kritis atau filsafat kreatif.Pengertian pertama adalah filsafat non-eksplisit disebut juga falsafah, yaitu butir-butir nilai dalam khasanah tradisi, adat dan budaya masyarakat yang sebagian tersimpan dalam bentuk kearifan lokal (localwisdom). Pengertian kedua yaitu filsafat sistematis yang artinya filsafat keilmuan akademik yang model dan bentuk pembelajarannya terwadahi dalam suatu lembaga pendidikan formal seperti perguruan tinggi yang di dalamya terdapat fakultas dan program studi yang mempelajari ilmu filsafat dan cabangcabang terkaitnya. Hal yang dimaksudkan dengan sistematikanya adalah cabangcabang filsafat pokok yaitu metafisika, epistemologi, etika, estetika (etika dan estetika disebut juga aksiologi), logika, dan metodologi.Itulah sebagai sebuah fakta dan realitas yang mencirikan filsafat sistematis dalam kaca pandang keilmuan.

Ada pun pengertian ketiga bahwa yang dimaksud dengan filsafat kritis atau filsafat kreatif adalah filsafat yang berusaha memahami hakikat realitas yang menekankan pada pandangan nilai-nilai moral, politik, dan agama. Kekayaan nilainilai falsafah dapat dijumpai dalam khazanah tradisi lisan masyarakat, sehingga 
falsafah dapat dijadikan pandangan hidup bermasyarakat dan aplikatif sebagai sikap dan perilaku keseharian. Dalam perspektif tersebut, maka pertunjukan wayang dapat mencakup kepada tiga bentuk filsafat tersebut.

Mencermati tentang falsafah, bukan dalam kerangka ilmu filsafat melainkan cenderung berada dalam konteks budaya. Walau bagaiamana pun tetap tradisi menjadi sumber rujukan pokok falsafah dengan kandungan nilai-nilai tradisinya. Keberadaan falsafah yang tersebar dalam tradisi lisan bersinergis dengan pandangan hidup yang merefleksikan dalam sikap dalam kese-harian sebagai mahluk yang berbudaya. Secara sudut pandang keilmuan, falsafah wayang berbeda dari filsafat wayang karena lebih mengacu kepada pandangan hidup yang termuat dalam pergelaran wayang sebagai praksis ajaran hidup. Filsafat wayang adalah sistem pengetahuan filosofis yang diformulasi dan dikontruksi dari pergelaran wayang dengan objek material /formal serta metodologi yang pas (Solichin, 2011,1).

Pada hakikatnya, wayang dapat memberikan gambaran lakon perikehidupan manusia dengan berbagai problematiknya, wayang sebagai etalase nilai dengan makna dan simboliknya yang dapat dijadikan sumber ajaran kehidupan untuk menghantarkan menuju manusia Indonesia seutuhnya. Melalui wayang, manusia dapat memperoleh pemahaman cakrawala baru tentang pandangan dan sikap hidup dalam memilih dan mewilah antara yang baik dan yang buruk, benar dan salah, dan seterusnya selalu dihadapkan dengan dua pilihan dalam proses perjalanan akbar manusia di muka bumi. Cerita wayang adalah lakon kehidupan manusia yang tersimbolkan oleh wayang dalam bentuk pernak-pernik nilainya. Selain memuat nilai spiritual yang dalam, juga wayang memuat ajaran budi pekerti, etik, estetik dan filosofi.Realitas inilah yang menghantarkan seni wayang Indonesia pada tahun 2003 telah dinobatkan oleh UNESCO sebagai Masterpiece of the Oral and Intagible Heritage of Humananity. Dasar pertimbangan utama UNESCO menganugrahkan wayang sebagai karya agung budaya yang mendunia adalah; pertama, wayang Indonesia sejak dulu digemari dan didukung oleh masyarakat luas, dan kedua, wayang Indonesia memiliki kualitas seni yang tinggi sehingga perlu dilestarikan dan dikembangkan agar bermanfaat bagi kemanusiaan. Kualitas seni yang tinggi itu biasa disebut edipeniadiluhung maksudnya indah dan menarik serta sarat dengan kandungan ajaran moral keutamaan hidup (Solichin, 2011,2).

Melalui pertunjukan wayang, kita dapat memahami dunia penuh makna yang tersimpan dalam bentuk khasanah nilai dan filosofinya. Nilai-nilai tersebut terkemas dalam keindahan seni yang disebut estetika pergelaran wayang. Dalam sebuah pertunjukan wayang yang baik, sudah barang tentu di dalamnya akan dijumpai kualitas tontonan yang dapat memberikan kesenangan, keindahan, kenyamanan dan hal-hal lainnya yang membangun suasana batin penonton menjadi larut dalam penikmatannya. Tentunya tidak hanya kemasan nilai estetik yang tersajikan dalam pertunjukan wayang, melainkan nilai etika dan falsafah menjadi bagian yang tak terpisahkan sebagai ruh pertunjukan dari aspek nilai dan makna. Dengan demikian, pertunjukan wayang secara realitas dan simbolik tampil sebagai sebuah tontonan, tuntunan, dan tatanan yang dapat menghibur serta menyampaikan ajaran sebagai referensi kehidupan pribadi, dalam bermasyarakat dan bernegara. Pada penelitian ini sebagai objek kajian kefilsafatannya, 
penulis mengangkat sebuah lakon Kumbakarna Gugur sajian Dalang Kondang Asep Sunandar Sunarya yang merupakan salah satu lakon unggulannya dalam karir mendalangnya. Lakon tersebut sangat representatif dijadikan objek kajian nilai yang dapat dijadikan sebagai sumber inspirasi dan media pendidikan budi pekerti.

Agar lebih memberikan penjelasan yang lebih rinci dalam membahas falsafah wayang, di bawah ini akan diruntut menjadi empar aspek pokok yang membangun falsafah wayang dalam bentuk pertunjukan wayang yaitu, 1). simbol wayang, 2). wayang perlambang hirup manusa, 3). wayang sebagai tontonan, tuntunan, dan tatanan, dan 4). Patet dalam karawitan wayang.

\section{Simbol Wayang}

Pertunjukan wayang adalah sebuah bentuk "teater total" dimana setiap lakon atau cerita wayang disajikan dalam pergelaran secara menyeluruh yang terungkap dalam bentuk simbol-simbol (Hazim Amir,1994). Melalui pertunjukan wayang, dapat dijumpai hal-hal yang berkaitan dengan pendidikan moral dan budi pekerti. Oleh karenanya aspek baik dan buruk selalu hadir ditampilkan dalam bentuk simbol tokoh-tokoh wayang dengan karakternya yang khas. Tentunya dalam pertunjukan wayang, tidak hanya sebatas persoalan nilai dan makna kehidupan yang mewilah antara hal kebaikan dan keburukan saja, melainkan nilai-nilai peradaban pun dapat dijumpainya, dan nilai-nilai kehidupan lainnya.Setiap lakon yang digarap atau dipertunjukkan oleh dalang, akan memiliki struktur atau pola urutan adegan yang dipertegas oleh penekanan materi dialog (antawacanawayang) berikut muatan simbol-simbolnya. Simbol mengenai kebaikan dan keburukan tersebut pada dasarnya tidak hanya sebatas menampilkan kisah kehidupan pribadi saja, akan tetapi juga menjangkau aspek kehidupan yang lebih luas dalam kehidupan bermasyarakat, berbangsa, dan bernegara. Realitas tersebut oleh orang Jawa, pergelaran wayang disebut wewayangane ngaurip, yaitu sebagai simbol kehidupan manusia yang terstruktur dari kehidupan manusia dimulai dari dalam kandungan, saat lahir, masa dewasa, dan saat ajal menjemputnya. Itulah sebuah gambaran nyata mengenai rotasi akbar perjalanan hidup manusia yang dikelilingi oleh simbolsimbol penuh makna, dan manusia harus mampu menerjemahkan dan merealisasikan makna tersebut dalam kehidupannya.

Pemahaman nilai-nilai simbolik dalam pertunjukan wayang dapat kita lihat dari lakon-lakon wayang dan unsur-unsur pendukungnya yang terbingkai dalam pergelaran wayang yang mengungkapkan keseluruhan kisah kehidupam manusia. Panggung kosong sebelum pergelaran wayang melambangkan alam semesta ciptaan Tuhan. Dua gedebog pisang jagat pagelaran wayang, melambangkan cosmos dunia atas dan dunia bawah, jagat ageung jagat kecil lambang strata masyarakat dimana terbagi menjadi masyarakat kalangan penguasa dan masyarakat rakyat biasa. Janturan(Jawa; simpingan) yang berderet samping kiri dan kanan dalang, melambangkan dua sisi kehidupan yang berpasangan, antara kebaikan dan keburukan, kebenaran dan kesalahan. Dalam tradisi pedalangan Sunda, janturan sebelah kiri dalang sebagai simbol kelompok manusia jahat, sedangkan janturan sebelah kanan dalang adalah kelompok manusia cinta kebenaran. Gunungan (kayon) yang ditertancap di atas gedebok dengan posisi miring ke kiri, 
melambangkan situasi akal, pikiran dan perilaku anak-anak yang masih labil dan cenderung suka melakukan hal-hal yang tidak benar. Gending lagu-lagu iringannya pun menggunakan Patet Nem yang melambangkan manusia dalam siklus usia anak-anak sampai remaja. Demikian juga letak gunungan menancap tegak di tengah jagat gedebog pergelaran, melambangkan situasi alam pikiran manusia dewasa yang sama-sama suka berbuat benar dan salah. Gending iringannya menggunakan Patet Sanga yang melambangkan siklus manusia dalam tahap dewasa sehingga mampu memilih mana yang benar dan salah. Adapun bagian ketiga, yaitu letak gunungan menancap miring ke kanan dan gending iringannya pun menggunakan Patet Manyuro, yang melambangkan manusia memasuki masa usia tua dengan kecenderungan lebih menyukai berbuat kebenaran dengan kematangan akal, pikiran, dan perilakunya (Hazim Amir, 1986,93-94).

Di bagian terakhir pembabakan (pembagian adegan) dalam pertunjukan wayang terdapat adegan penutup berupa tancep kayon sebagai pertanda pertunjukan wayang telah berakhir. Ketika dalang menutup pertunjukannya dengan ditandai tancep kayon, maka gending karawitan wayang pun mengalun mengiringi penonton bubaran, mereka kembali ke rumahnya masing-masing dengan membawa bekal wejangan dan hiburan yang didapatkan melalui tontonan wayang. Semua wayang yang berjejer (dijantur) di sebelah kiri dan kanan dalang, termasuk wayang yang dipergunakan oleh dalang, satu persatu dimasukkan lagi ke dalam kotak wayang. Gamelan iringan wayang yang ditabuh oleh para pangrawit, juga kembali dibereskan masuk ke dalam kotak atau wadah yang biasa dipergunakan untuk menyimpan gamelan sesuai bentuk dan ukurannya masing-masing. Panggung kembali menjadi kosong, tidak ada aktivitas pertunjukan, bahkan panggungnya pun dibongkar sehingga tempat tersebut, benarbenar menjadi tanah atau pekarangan yang kosong tidak ada bangunan atau panggung pertunjukan. Itu semua adalah simbol dunia ketika kehidupan manusia dan mahluk hidup lainnya telah berakhir, dunia kembali menjadi kosong, dan itulah zaman telah berakhir yang disebut kiamat.Itulah siklus simbol yang tergambarkan dalam pertunjukan wayang, sebagai gambaran hidup manusia ketika di dunia dimulai dari lahir, masa anak-anak, remaja, dewasa, tua hingga kembali mati meninggalkan dunia fana menuju kehidupan sesungguhnya di alam akhirat.

\section{Wayang Perlambang Hirup Manusa}

Dalam sebuah rumpaka (syair) lagu kepesindenan sering dijumpai kata-kata sebagai berikut:

$$
\begin{aligned}
& \text { wayang teh ngandung perlambang } \\
& \text { perlambang hirup manusa } \\
& \text { manusa teu kumawasa } \\
& \text { darma wawayangan bae } \\
& \text { wayang hirup ku dalangna } \\
& \text { dalang nu ngusikeunana } \\
& \text { wayang hanut maring dalang } \\
& \text { dalang hanut maring wayang... }
\end{aligned}
$$

(wayang itu mengandung lambang lambang kehidupan manusia manusia tidak berkuasa hanya sekadar bermain wayang

wayang hidup oleh dalang dalang yang menggerakan wayang menyatu dengan dalang dalang menyatu dengan wayang)

Rumpaka (syair) tersebut mengandung pengertian yang sangat dalam sebagai sebuah pemaknaan tentang kehidupan manusia yang digambarkan dalam kosmos panggung pertunjukan wayang. Panggung 
pertunjukan wayang tidak hanya dipandang sebagai panggung hiburan semata, melainkan panggung pertunjukan wayang dipandang sebagai panggung kehidupan manusia di muka bumi. Dengan demikian semakin jelas, bahwa pertunjukan wayang pada hakikatnya alalah lambang yang bersifat religius-mistis, yaitu lambang kehidupan manusia dari lahir sampai mati sebagaimana tergambarkan dalam struktur lakon dalam pertunjukan wayang.

Solichin menginterpretasikan wayang sebagai wewayanganengaurip, dalam arti bahwa pergelaran wayang merupakan cermin kehidupan manusia.

Pergelaran wayang tidak lagi diperuntukkan hanya bagi seni yang menggunakan efek bayang-bayang, tetapi dipandang sebagai seni pertunjukan yang merefleksikan atau mencerminkan kehidupan manusia. Bayang-bayang lalu mendapat tafsir sebagai bayangan kehidupan atau wewayangane ngaurip (Solichin, 2011,7). Persoalan bahwa wayang ditafsir sebagai sebuah bentuk kekuatan makna atau simbol yang terdapat dalam hampir semua aspek pertunjukan wayang, maka sangatlah beralasan bahwa pertunjukan wayang dapat dipandang sebagai dunia penuh simbol, penuh lambang kehidupan manusia.

Dengan demikian, makna wayang sebagai wayang perlambang hirup manusia atau masyarakat Jawa menyebut wewayanganengaurip menjadi daya tarik tersendiri dimata penontonnya. Penonton akan dapat bercermin pada wayang dengan tokoh yang berperan pada lakon, sehingga akan muncul pertanyaan dirinya, peran apakah yang saya lakukan di dalam kehidupan sehari-hari? Tokoh wayang mana yang sesuai dengan sifat dan karateristik yang dimilikinya, maka terjadilah proses perenungan dari benak para penonton, sebagai hasil menikmati dan mencermati pertunjukan wayang. Inilah salah satu bukti sekaligus yang mencirikan bentuk pertunjukan wayang, yang dapat menghipnotis penontonnya ikut larut dalam penikmatan secara total.Penonton dibawa ke dunia perenungan yang kuat melalui daya kenang dan dorongan merenung, sehinga tidak membosankan menonton wayang dari panggung satu ke panggung lainnya, terlebih dalangnya adalah dalang idolanya. Secara tidak sadar, penonton telah terbawa emosi dan empatinya dalam proses penikmatan sebagai penonton wayang yang baik, yang pada akhirnya penonton dapat memetik hikmah yang dalam dari peristiwa lakon yang disajikan oleh sang dalang. Hal-hal tersebut merupakan fakta dan realitas dari fenomena yang terjadi diseputar pendapat para penikmat wayang yang telah diminta komentar dan tanggapannya dari para narasumber yang telah ditentukan dalam pengumpulan data penelitian.

\section{Wayang sebagai Tontonan, Tuntunan, dan Tatanan}

Kehadiran wayang sebagai bentuk pertunjukan yang merakyat dengan ciri-ciri keteatrikalan di tengah-tengah masyarakat, sudah tidak diragukan lagi keberadaannya. Sebagai salah satu bukti yang sangat faktual, yakni dari sejak dulu sampai sekarang, pertunjukan wayang masih tetap digemari oleh masyarakat sebagai tontotonan yang segar, komunikatif, edukatif, dan tentunya sangat menghibur. Penonton wayang terdiri atas berbagai lapisan masyarakat, mulai dari orang tua, remaja, anak-anak, masyarakat awam, masyarakat penggemar (maniak wayang), cendikiawan, birokrat dan masyarakat lainnya.Pada prinsipnya semua lapisan masyarakat yang menonton pertunjukan wayang dapat menikmati dan 
mengambil hikmah sesuai dengan bekal pengetahuan tentang wayang dan kepekaan estetiknya.

Berbagai indikator respon masyarakat dalam menikmati tontonan pertunjukan wayang antara lain, orang akan merasa tertarik hanya melalui gerakan tarian wayang (sabet), lalu tertarik dengan muatan dialognya (antawacana), tertarik dengan bahasanya (paramasastra), guyonannya (banyol), kakawennya dan aspek-aspek lainnya. Dari ragam aspek pertunjukan yang menjadi modal bekal apresiasi pentonton tersebut, pada prinsipnya daya sensibilitas penonton wayang bermuara pada aspek estetika, etika, dan falsafah. Bekal pengalaman estetik yang dimiliki oleh penonton wayang, akan sangat berpengaruh terhadap kepekaan menikmati tonotonan wayang yang tidak sekadar rame dan tidak ramenya. Selanjutnya persoalan etika dalam pertunjukan wayang, menjadi sesuatu yang sangat bermakna ketika penonton mampu membaca dan menyimak dengan cermat terhadap muatan nilai-nilai praktik kehidupan yang muncul dari peran masingmasing tokoh dan karakter wayang. Demikian pula halnya perihal nilai-nilai kefilsafatan yang terdapat pada lakon dalam pertunjukan wayang, dipandang sebagai sesuatu yang bermakna tinggi dalam memahami nilai-nilai luhur kehidupan. Tiga bentuk nilai fundamental inilah yang dapat membentuk sikap, pemikiran, dan perilaku manusia yang bermoral tinggi, beretika, berwawasan ilmu, bersosio-cultural yang kuat sebagai manipestasi kehidupan berbangsa, bernegara, dan berbudaya luhur.

Seiring dengan berkembangnya zaman disertai dengan terjadinya perubahan dengan berbagai bentuk manipestasinya, maka bentuk pertunjukan wayang pun kini telah mengalami perubahan.Perubahan yang paling mendasar adalah dalam hal for- mat atau pola pertunjukan wayang yang berkisar pada format pertunjukan tradisi dan format pertunjukan kekinian. Hadirnya piranti teknologi sebagai konsekuensi imbasnya dari zaman teknologi, menjadikan pertunjukan wayang semakin lengkap dengan didukung oleh peralatan elektronik yang memadai.Dengan demikian, bentuk tontonan wayang zaman sekarang tampak lebih semarak dan artistic, baik secara audio maupun visual yang tentunya berbeda dengan bentuk tampilan wayang pada zaman dulu sebelum hadirnya teknologi canggih. Dampak dari adanya perubahan bentuk dan format yang banyak didukung oleh tuntutan era teknologi terhadap pertunjukan wayang, secara otomatis berdampak pula terhadap animo masyarakat sebagai penikmat wayang. Penonton semakin dimanjakan dengan kehadiran teknologi sound system, lighthing, artistikdekoratif, termasuk bentuk tampilan boneka wayang dan instrumen gamelan yang memadai baik secara kualitas maupun kuantitas. Inilah sebuah fakta dan realitas yang terjadi dan berlangsung dalam sejarah perjalanan seni pertunjukan wayang di tengah-tengah masyarakat global.

Setelah wayang ditempatkan sebagai sebuah bentuk tontonan yang representatif bagi masyarakat, maka dengan sendirinya pertunjukan wayang pun menjadi sebuah bentuk tontonan yang berdaya nilai tinggi dengan kandungan-kandungan makna simboliknya.Kekuatan muatan nilai-nilai luhur seperti inilah yang menjadi salah satu ciri khas pertunjukan wayang dapat bertahan abadi, selalu digemari, ditonton, dan dimaknai oleh penikmatnya.Kondisi inilah yang perlu terus dipertahankan dan dipelihara agar wayang tetap menjadi bagian dari kehidupan manusia sepanjang masa. Dengan demikian, pertunjukan wayang tidak sekadar sebagai tontotonan, melainkan 
wayang sebagai tuntunan bagi penikmatnya menuju kepada tataran manusia yang berbudi pekerti luhur, dalam jargon budaya Sunda menjadikan manusia Sunda paripurna, Sunda nyantana, depe-depe handap asor, luhur budi hade basa, cageur bageur bener pinter.

Tahap berikutnya setelah wayang dipandang sebagai bentuk tontonan dan tuntunan sebagai roh hakikinya dalam konteks makna dan hikmah dari pertunjukan wayang, maka pertunjukan wayang pun berwujud sebagai tatanan yang berkaitan erat dengan nilai estetika pertunjukan wayang. Melalui keindahan yang terpancarkan dalam pamor dan aura gemerlapnya sajian pertunjukan wayang, menjadikan daya tarik yang kuat bagi penontonnya. Panggung pertunjukan wayang tampak begitu megah, seperti halnya dalam bentuk panggung pertunjukan wayang golek, tampak terpampang jagat gedebog pisang (jagat pagelaran) tepat di depan dalang. Samping kiri dan kanan dalang berjejer janturan (Jawa; simpingan) wayang. Di belakang terhampar gelaran instrumen gamelan wayang dengan tata letak yang nampak harmoni sesuai dengan fungsi dari masingmasing waditra alat yang ditabuh oleh para pangrawit (wiyaga). Tugas para penabuh (pangrawit) sudah tertata dan teratur dengan rapih sesuai dengan tugas peranan waditra yang ditabuhnya. Untuk mendukung kemantapan arah pandang penonton dalam menikmati pandangannya, maka panggung wayang didukung oleh tata lampu (lighthing) yang memadai. Dengan demikian, pandangan penonton melihat wayang di atas jagat pagelaran tersebut, akan lebih jelas dan fokus dapat melihat detail wajah karakter tokoh wayang dan pakaiannya. Tidak terlewatkan penataan sound system yang sangat berperan besar dalam membangun hasil suara atau bunyibunyian, baik suara dalang, sinden maupun suara lantunan gamelan yang ditabuh. Unsur-unsur estetik inilah sebagaimana telah diuraikan pada bagian depan, yang kesemuanya merupakan bentuk tatanan artistik pertunjukan wayang dengan kekuatan harmoni usnur-unsur terkait dalam satu kesatuan yang utuh pada pertunjukan wayang.

\section{SIMPULAN}

Pertunjukan wayang golek selama ini masih tetap dijadikan sarana hiburan rakyat, yang di dalamnya memuat nilai-nilai kehidupan dengan beragam makna dan simbol penafsiran yang dapat dimaknai oleh manusia sebagai penikmat wayang. Melalui wayang, manusia dapat memotret diri dengan cara mencoba mencermati dan memaknai salah satu tokoh wayang yang digemari termasuk karater dari tokoh wayang tersebut.

Pada hakikatnya, wayang dapat memberikan gambaran lakon perikehidupan manusia dengan berbagai problematiknya, wayang sebagai etalase nilai dengan makna dan simboliknya yang dapat dijadikan sumber ajaran kehidupan untuk menghantarkan menuju manusia Indonesia seutuhnya. Melalui wayang, manusia dapat memperoleh pemahaman cakrawala baru tentang pandangan dan sikap hidup dalam memilih dan mewilah antara yang baik dan yang buruk, benar dan salah, dan seterusnya selalu dihadapkan dengan dua pilihan dalam proses perjalanan akbar manusia di muka bumi. Cerita wayang adalah lakon kehidupan manusia yang tersimbolkan oleh wayang dalam bentuk pernak-pernik nilainya. Selain memuat nilai spiritual yang dalam, juga wayang memuat ajaran budi pekerti, etik, estetik, dan filosofi. 
Wayang merupakan hasil cipta, rasa, dan karsa manusia Indonesia karena proses daya spiritual.Pengamatan yang mendalam terhadap wayang menunjukkan wayang bukan seni yang bertujuan untuk kepuasan biologis, tetapi memberikan kepuasan batiniah. Menonton pergelaran wayang merupakan proses instrospeksi intuitif terhadap simbol-simbol disertai pembersihan intelektual dan penyucian moral sehingga mendapatkan pencerahan rohani. Wayang memakai logika dongeng tetapi logika itu atas dasar nilai-nilai realitas seharihari. Wayang merupakan cerminan kehidupan manusia secara konkret. Pergelaran wayang merupakan proses instrospeksi intuitif terhadap simbol.

Pertunjukan wayang dipandang sebagai etalase nilai dan norma kehidupan yang di dalamnya memuat aspek-aspek nilai spiritual, moralitas, dan nilai-nilai normatif lainnya. Melalui kedalaman nilai-nilai tersebut, maka pertunjukan wayang sangat berpengaruh besar terhadap kehidupan manusia dalam kontek kehidupan berbangsa, berbudaya dan beragama.

\section{Daftar Pustaka}

Cahya

2009 Struktur Dramatik Lakon Wayang, Jurnal Panggung, STSI, Bandung, Volume 5, No.1

2011 Memahami Gaya Pedalangan Sunda, Jurnal Resital ISI Yogyakarta, Volume 12. No.2

Salmun, M.A.

Padalangan. Jakarta: Balai Pustaka, 1961.

Solichin

2011 Falsafah Wayang, Intagible Heritage Of Humanity, Jakarta; Yayasan Senawangi

Slamet Sutrisno, dkk

2009 Filsafat Wayang, Jakarta: Yayasan

Senawangi
Soedarsono, RM.

1999 Metodologi Penenlitian Seni Pertunjukan dan Seni Rupa, Bandung: MSPI.

Guritno, Pandam. Wayang Kebudayaan Indonesia dan Pancasila. Jakarta: UI Press,1988.

Hadiprayitno, Kasidi.

2009 Filsafat Keindahan, Suluk Wayang Kulit Purwa Gaya Yogyakarta. Yokyakarta: Bagaskara.

Hamzah, Amir.

1994 Nilai-Nilai Etis Dalam Wayang. Jakarta: Sinar Harapan.

Soetarno,

2005 Pertunjukan Wayang \& Makna Simbolisme. Surakarta: STSI Press .

Soepandi, Atik.

1885 Wayang Golek Gaya Priangan. Bandung: Bina Cipta.

$---$

1988 Tetekon Padalangan Sunda. Jakarta: Balai Pustaka.

Van Groenendael, Victoria M.Clara.

1987 Dalang Di Balik Wayang. Jakarta: Pustaka Utama Grafiti.

$$
\text { Senawangi }
$$

